\title{
SYMPTOMATOLOGY, PROPHYLAXIS, TREATMENT, AND PUBLIC AWARENESS IN THE FIELD OF THE CHRONIC VENOUS DISEASES IN THE FEMALE POPULATION OF POLAND: AN EPIDEMIOLOGICAL STUDY OF A REPRESENTATIVE GROUP OF THE ADULT POPULATION
}

\author{
Tomasz Urbanek', Tomasz Zubilewicz² \\ 'Department of General Surgery, Vascular Surgery, Angiology, and Phlebology, Medical \\ University of Silesia, Katowice \\ ${ }^{2}$ Department of Vascular Surgery and Angiology, Lublin Medical University, Lublin
}

\begin{abstract}
Chronic venous disease (CVD) is one of the most commonly present and diagnosed vascular system pathologies, and it influences the health status of the general population and the quality of life of many individuals. Among the significant factors that influence the presence and severity of CVD is patient gender, and some known and suspected risk factors have to be considered. In this study, the prevalence of symptoms and signs of CVD in the female population of Poland was evaluated. Additionally, the levels of knowledge and public awareness related to CVD and its risk factors, prophylaxis methods, and treatments were evaluated. The study was performed with a representative group of 604 adult females (aged 20-80 years) from all Polish provinces via computer-assisted telephone interviews. The study was commissioned by the Polish Society of Phlebology and supported by a scientific research grant from the HASCOLEK company.
\end{abstract}

Key words: chronic venous disease, epidemiology, symptomatology.
ORIGINAL PAPER

Phlebological Review 2016; 24, 2-3: 29-37

DOI: https://doi.org/10.5114/pr.2016.65516

Submitted: 30.05 .2016

Accepted: 23.08.2016

\author{
ADDRESS FOR CORRESPONDENCE \\ dr hab. Tomasz Urbanek \\ Department of General Surgery, Vascular \\ Surgery, \\ Angiology, and Phlebology \\ Medical University of Silesia \\ Ziołowa 45/47, 40-635 Katowice \\ Poland \\ e-mail: urbanek.tom@interia.pl
}

\section{INTRODUCTION}

Chronic venous diseases (CVDs) are among the most commonly present vascular pathologies. Chronic venous disease treatment and the treatment of the complications of CVD generate significant costs in the health care system in addition to general social costs [1-4]. Despite the significant worsening of the patients' quality of life, many patients are seen by physicians only in the very late phase of disease advancement. According to a study performed by Jawień et al., venous crural ulcers occur in $1.5 \%$ of the adult population in Poland, including $0.5 \%$ of patients with active venous ulcers [5]. In the same study, which concerned adult patients who visited their general practitioners (GPs) (independent of the reason for the GP consultation), the symptoms and signs of CVD were found in $48 \%$ of the female population and in $37 \%$ of the males [5]. Currently, there is still a lack of the good projected and properly performed epidemiological studies dedicated to chronic venous disease that are related to the general unselected population in our country [5-9]. Moreover, the data concerning the potential and clinically implemented treatment methods in Poland need to validated [6-9]. Due to the lack of reimbursements for compression, sclerotherapy, new minimal invasive ablation methods, and pharmacotherapy for CVD (only open classical surgical interventions are covered by the state national insurance), there is potentially no reliable access to the preferred treatment methods in centres that treat phlebological patients in our country (many of the procedures are performed in private phlebological centres that are not associated with the national insurance system). We are also not able to answer the following questions: How large is the population of patients with CVD who are properly treated? And what is the level of patient knowledge concerning CVD prophylaxis and treatment possibilities? In this regard, all studies and research that focus on the epidemiological situation of CVD and its treatment modalities in our country seem to be clinically justified. The aim of the current study was to assess the prevalence of the symptoms and signs of chronic venous diseases in the population of the adult females in Poland. Additionally, the levels of knowledge and public awareness about CVD in the representative group of the female population were also evaluated. 


\section{MATERIAL AND METHODS}

The study was performed from 31 March 2014 until 11 April 2014 on a group of 604 adult females aged from 20 to 80 years from all provinces of Poland. The research was conducted based on results from computer-assisted telephone interviews that were performed with the help of an agency that specialises in public opinion investigations (IMAS International Sp. z o.o.). The interviews targeted a representative group of the female population of Poland. During the telephone interviews, a special, previously prepared questionnaire was used. The numbers of stationary telephones and mobile telephones were randomly selected. In the study group of 604 female patients, the following age intervals were defined: $20-30$ years $-21 \%$; $31-45$ years $-26.8 \%$; $46-60$ years $-28.1 \%$; and $61-80$ years $-24 \%$. As mentioned before, participants from all provinces of Poland were recruited for this study. The distributions of the study population by age, province of residency, and class of the place of residency reflected the distributions of these variables in the general Polish population aged 20-80 years after weighting the data according to educational level (the age categories, provinces, and sizes of the places of the residency were cross-matched in the quoted plan, and the deviation did not exceed $3 \%$ ). $38.9 \%$ of the studied population lived in rural areas, $24.1 \%$ lived in cities with $\leq 50,000$ citizens, $16 \%$ lived in cities with 51,000-100,000 citizens, $16 \%$ lived in cities with $>200,000$ inhabitants, and 5\% were residents of the capital Warsaw. In the study group, physical work activities were reported by $20.6 \%$ of the participants, and intellectual work was reported by $24.6 \%$. Of the population, $24.6 \%$ were unemployed or looking for a job, and $35.1 \%$ were retired or receiving disability living allowances. Among the respondents, 37\% had completed basic primary education, 39.8\% had completed secondary school, and $23.1 \%$ had obtained higher levels of education. During the study, the following problems and questions were defined and accounted for when creating the study questionnaire:
- an assessment of the prevalence of the signs and symptoms of chronic venous diseases and their complications in the adult female population of Poland,

- an assessment of the prevalences of CVD risk factors in the study population (i.e. factors related to daily habits and activities, work, lack of physical activity, and positive family histories),

- an evaluation of the CVD treatment modalities and proper access to medical care,

- an evaluation of the knowledge and public awareness about CVD risk factors and potential complications of CVD including varicose vein complications,

- an assessment of knowledge sources concerning CVD,

- an evaluation of the patients' satisfaction concerning their levels of knowledge about CVD treatment and prevention measures, and an evaluation of their expectations concerning the availability of this knowledge in the media.

\section{RESULTS}

In the study population, subjective complaints that were potentially related to the presence of CVD were reported by most of the respondents. Seventy per cent of the cases reported heaviness and fatigue in the lower legs that worsening after long periods of standing or sitting. This complaint was more frequently present in the older population $(62.5 \%$ in the $20-30$-year group and $74.3 \%$ in the 61-80-year-old group; Table 1). Pain in the lower extremities was reported by $37 \%$, and cramps within the lower legs (especially after long periods of standing or sitting) were present in $46 \%$ (with a prevalence of $61 \%$ prevalence in the age group above 60 years old; Table 1).

Similar to the symptoms, a relatively high proportion of the investigated population reported CVD signs (Table 2). Only $13 \%$ the respondents reported no signs or symptoms of CVD.

Based on the study results, the significant progression of the occurrence of CVD symptoms as well as progression of the disease advancement with an increasing age of the respondents should be emphasised. The rate of varicose

Table 1. The prevalence of subjective symptoms related to the lower legs that are potentially related to CVD in the analysed female population

\begin{tabular}{lccccc}
\hline & $\begin{array}{c}\text { \% of the study group with } \\
\text { reported symptoms }\end{array}$ & $20-30$ yrs. & $31-45$ yrs. & $46-60$ yrs. & $61-80$ yrs. \\
\hline $\begin{array}{l}\text { Feeling of heaviness and fatigue in the lower limbs after } \\
\text { a longer period of standing or sitting }\end{array}$ & $70 \%$ & $62.5 \%$ & $68.1 \%$ & $72.7 \%$ & $74.3 \%$ \\
\hline Leg pain, worsening after a longer period of standing or sitting & $37 \%$ & $28.4 \%$ & $31.2 \%$ & $44.9 \%$ & $42.5 \%$ \\
\hline Lower leg cramps, worsening after longer sitting or standing & $46 \%$ & $37.1 \%$ & $36.4 \%$ & $48.1 \%$ & $61.1 \%$ \\
\hline Itchy skin of the lower leg in the crural region & $12 \%$ & $5 \%$ & $7 \%$ & $11 \%$ & $18 \%$ \\
\hline
\end{tabular}


Table 2. The presence of the signs of CVD in the evaluated population

\begin{tabular}{lccccc}
\hline & $\%$ of the population with signs & $\mathbf{2 0 - 3 0}$ yrs. & $\mathbf{3 1 - 4 5}$ yrs. & $\mathbf{4 6 - 6 0}$ yrs. & $\mathbf{6 1 - 8 0}$ yrs. \\
\hline Reticular veins, telangiectasies & $51 \%$ & $31.1 \%$ & $486 \%$ & $56.5 \%$ & $65.1 \%$ \\
\hline Lower leg swelling & $40 \%$ & $22.4 \%$ & $42 \%$ & $41 \%$ & $51.7 \%$ \\
\hline Varicose veins & $32 \%$ & $11.1 \%$ & $282 \%$ & $35.4 \%$ & $50.1 \%$ \\
\hline Discoloration, trophic changes & $18 \%$ & $8.8 \%$ & $8.3 \%$ & $23.9 \%$ & $29.4 \%$ \\
\hline Non-healing or difficult-to-heal lower leg ulcerations & $1.4 \%$ & $1.9 \%$ & $0.3 \%$ & $0.3 \%$ & $3.4 \%$ \\
\hline
\end{tabular}

vein occurrence in the entire study population was $32 \%$, and more than $50 \%$ of the patients over the age of 60 years reported both varicose veins and leg swelling. Moreover, these complaints were also present in the younger population; in the 31-45-year-old group, leg swelling was reported by $42 \%$ of the respondents, and varicose veins were reported by $28.2 \%$. Additionally, the relatively high prevalence of leg ulcers in the patients above 60 years old (3.4\%) should also be emphasised. Clinical signs were often correlated with the presence of clinical symptoms; the coexistences of signs and symptoms are presented in Table 3.

Regarding the data in Table 3, the information concerning the groups of patients with leg ulcers should be interpreted with caution due to the limited number of cases, particularly in the younger subpopulations. In contrast, in the majority of the groups, the common coexistence of symptoms and signs that are potentially related to chronic venous disease should be emphasised. Among the female patients with varicose veins, $78 \%$ reported feelings of heaviness and fatigue in the lower limbs after long periods of standing or sitting.

Regarding the group of patients with signs and symptoms of chronic venous disease, a question about the importance of these signs and symptoms during the patient's daily activities and duties was included in the questionnaire (Fig. 1). The answers were provided as ratings that ranged from 1 to 5 points $(1$ - "no problem at all" and 5 - "they are a very severe problem for

Table 3. The coexistence of clinical signs and symptoms of chronic venous disease in the examined female population

\begin{tabular}{|c|c|c|c|c|c|c|c|c|c|}
\hline $\begin{array}{l}\% \text { of signs and symptoms } \\
\text { coexistence - evaluated } \\
\text { in the relationship to the } \\
\text { symptom or sign in the } \\
\text { column title }\end{array}$ & $\begin{array}{c}\text { Varicose } \\
\text { veins }\end{array}$ & $\begin{array}{l}\text { Telan- } \\
\text { giecta- } \\
\text { sies }\end{array}$ & $\begin{array}{l}\text { Leg } \\
\text { swel- } \\
\text { ling }\end{array}$ & $\begin{array}{c}\text { Feeling of } \\
\text { heaviness } \\
\text { and fatigue } \\
\text { in the lower } \\
\text { limbs after a } \\
\text { longer period } \\
\text { of standing or } \\
\text { sitting }\end{array}$ & $\begin{array}{l}\text { Leg pain, } \\
\text { worse- } \\
\text { ning after } \\
\text { a longer } \\
\text { period of } \\
\text { standing } \\
\text { or sitting }\end{array}$ & $\begin{array}{l}\text { Lower leg } \\
\text { cramps, } \\
\text { worsening } \\
\text { after } \\
\text { longer } \\
\text { sitting or } \\
\text { standing }\end{array}$ & $\begin{array}{l}\text { Itchy } \\
\text { skin of } \\
\text { the lower } \\
\text { leg in the } \\
\text { crural } \\
\text { region }\end{array}$ & $\begin{array}{l}\text { Discolo- } \\
\text { uration, } \\
\text { trophic } \\
\text { changes }\end{array}$ & $\begin{array}{l}\text { Non- } \\
\text {-healing or } \\
\text { difficult- } \\
\text {-to-heal } \\
\text { lower leg } \\
\text { ulcerations }\end{array}$ \\
\hline Varicose veins & & $51 \%$ & $43 \%$ & $35 \%$ & $41 \%$ & $40 \%$ & $60 \%$ & $67 \%$ & $56 \%$ \\
\hline Telangiectasies & $68 \%$ & & $51 \%$ & $44 \%$ & $46 \%$ & $46 \%$ & $68 \%$ & $77 \%$ & $58 \%$ \\
\hline Leg swelling & $52 \%$ & $47 \%$ & & $45 \%$ & $51 \%$ & $47 \%$ & $68 \%$ & $60 \%$ & $74 \%$ \\
\hline $\begin{array}{l}\text { Feeling of heaviness and } \\
\text { fatigue in the lower limbs after } \\
\text { a longer period of standing } \\
\text { or sitting }\end{array}$ & $79 \%$ & $76 \%$ & $84 \%$ & & $88 \%$ & $81 \%$ & $93 \%$ & $86 \%$ & $77 \%$ \\
\hline $\begin{array}{l}\text { Pain, worsening after a longer } \\
\text { period of standing or sitting }\end{array}$ & $57 \%$ & $49 \%$ & $58 \%$ & $53 \%$ & & $57 \%$ & $68 \%$ & $58 \%$ & $68 \%$ \\
\hline $\begin{array}{l}\text { Lower leg cramps, worsening } \\
\text { after longer sitting or standing }\end{array}$ & $64 \%$ & $55 \%$ & $61 \%$ & $57 \%$ & $66 \%$ & & $73 \%$ & $72 \%$ & $70 \%$ \\
\hline $\begin{array}{l}\text { Itchy skin of the lower leg in } \\
\text { the crural region }\end{array}$ & $23 \%$ & $19 \%$ & $21 \%$ & $15 \%$ & $19 \%$ & $17 \%$ & & $28 \%$ & $46 \%$ \\
\hline Discolouration, trophic changes & $40 \%$ & $35 \%$ & $30 \%$ & $22 \%$ & $25 \%$ & $27 \%$ & $44 \%$ & & $56 \%$ \\
\hline $\begin{array}{l}\text { Non-healing or difficult-to-heal } \\
\text { lower leg ulcerations }\end{array}$ & $4 \%$ & $3 \%$ & $4 \%$ & $2 \%$ & $3 \%$ & $3 \%$ & $8 \%$ & $6 \%$ & \\
\hline
\end{tabular}


me"). Only $28 \%$ of the respondents specified that the above-mentioned symptoms and signs of CVD did not create any problems in their daily lives. Among the other patients, various levels of complaint severity were observed $(19 \%$ of the respondents confirmed that the presence of the disease created very significant/severe problems; Fig. 1).

Among the study group, $45.1 \%$ of the respondents were professionally active, including $42.9 \%$ of respondents who were required to sit at work, $12.8 \%$ who performed their work in the standing position, and $44.3 \%$ of respondents who defined their professional work as requiring walking. In the overall examined population, the median time spent sitting during professional work was four hours, and the median time spent in the standing position was six hours. Less than two hours of sitting was reported by $7.1 \%$ of the respondents, $2-4$ hours was reported by $33.5 \%$, 4-8 hours was reported $37.1 \%$, and more than eight hours of sitting was reported by $21.4 \%$. More than two hours of daily of standing was reported by $9.8 \%$ of the participant, $2-4$ hours was reported by $19.1 \%, 4-8$ hours was reported by $34.2 \%$, and more than eight hours of standing was reported by $35.6 \%$.

Potential risk factors for CVD development and progression other than professional activities were investigated in this study. Among all respondents, 58.6\% reported the presence of varicose veins in their parents, grandparents, or siblings, and $62.6 \%$ of the population drank alcohol (1.5\% a few times per week, $13.9 \%$ a few times per month, and $46.7 \%$ once per month or less). The performance of sport activities was reported by $49.9 \%$ of the respondents, including $9.8 \%$ who performed such activities five times per month, $13.6 \%$ who did so $6-12$ times per month, and $26 \%$ who did so more than 12 times per month. $23.9 \%$ of the questioned population were smokers.

Despite the high prevalence of symptomatic patients, the rate of treated or continuously controlled patients remained very low. Among the subpopulation of treated patients with disease symptoms and signs, only $35.3 \%$ visited their physician (currently or in the past). Another $22.1 \%$ of this population consulted with pharmacy staff

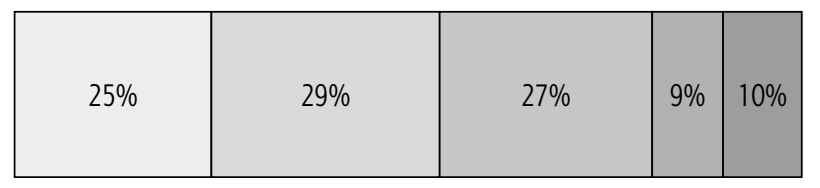

$$
\begin{aligned}
& \square 1 \text { - no problem } \\
& \square 2 \\
& \square 3 \\
& \square 4 \\
& \square 5 \text { - serious problem }
\end{aligned}
$$

Fig. 1. Results for the question "Do the reported complaints cause significant problems in daily activities and duties?" from the group of symptomatic patients about their complaints and CVD problems. Among the group of respondents who visited their physician, 56.1\% received a clear explanation of the aetiology and mechanisms of the disease. In the overall study population, only $33.8 \%$ of the patients who ever experienced a physician consultation (independent of the reason for the consultation) were asked about complaints that were potentially related to the lower extremities (including swelling, pain, and the presence of varicose veins). Moreover, $86.8 \%$ of the study population emphasised that GPs should focus greater attention on problems related to varicose veins and the potentially related complications.

Regarding the reported data, disease duration was also considered. In $33.2 \%$ of the respondents, the duration of the presence of the varicose veins was longer than 20 years, in $23 \%$ the duration was more than 10 years, and in $20.3 \%$ the duration was between 5 and 10 years. In response to the question "Who among physicians should primarily care for patients with varicose veins?", most of the patients mentioned vascular surgeons (34\%) followed by cardiologists $(6.1 \%)$, general surgeons $(2.5 \%)$, internal medicine specialists $(2.5 \%)$, angiologists $(2 \%)$, dermatologists $(1.3 \%)$, and more rarely other specialists. Phlebologists were mentioned only by $0.7 \%$ of the questioned population. One important element that is related to prophylaxis and early treatment implementation is the patients' education. However, as documented in this study, professional medical information concerning varicose veins was primarily obtained not from medical staff but rather from other non-medical sources; only $22.4 \%$ of the respondents specified their physician as the source of knowledge source, whereas $32.2 \%$ indicated that their knowledge came from TV, radio, or internet adverts and information programmes (Fig. 2). Regarding the level of knowledge concerning chronic vein disease, a large group of patients confirmed a lack or low level of proper education related to disease prophylaxis and management (including self-management, Figs. 3 and 4). The respondents were also questioned about the need for education and publicity concerning CVD in the media (Fig. 5).

The questionnaire prepared for this study included questions concerning current and previous treatment methods (answered by the group of symptomatic patients; Fig. 6). The responses revealed that locally or orally administered drugs, diet supplements, and leg elevation were the primary CVD therapies utilised by the examined female population in Poland. However, due to the study's methodology, we were unable to determine the proportion of the population that was being treated according to advice from a physician consultation or the proportion of the population that was using self-treatment methods.

\section{DISCUSSION}

Chronic venous diseases have a significantly higher prevalence among the female population and are 


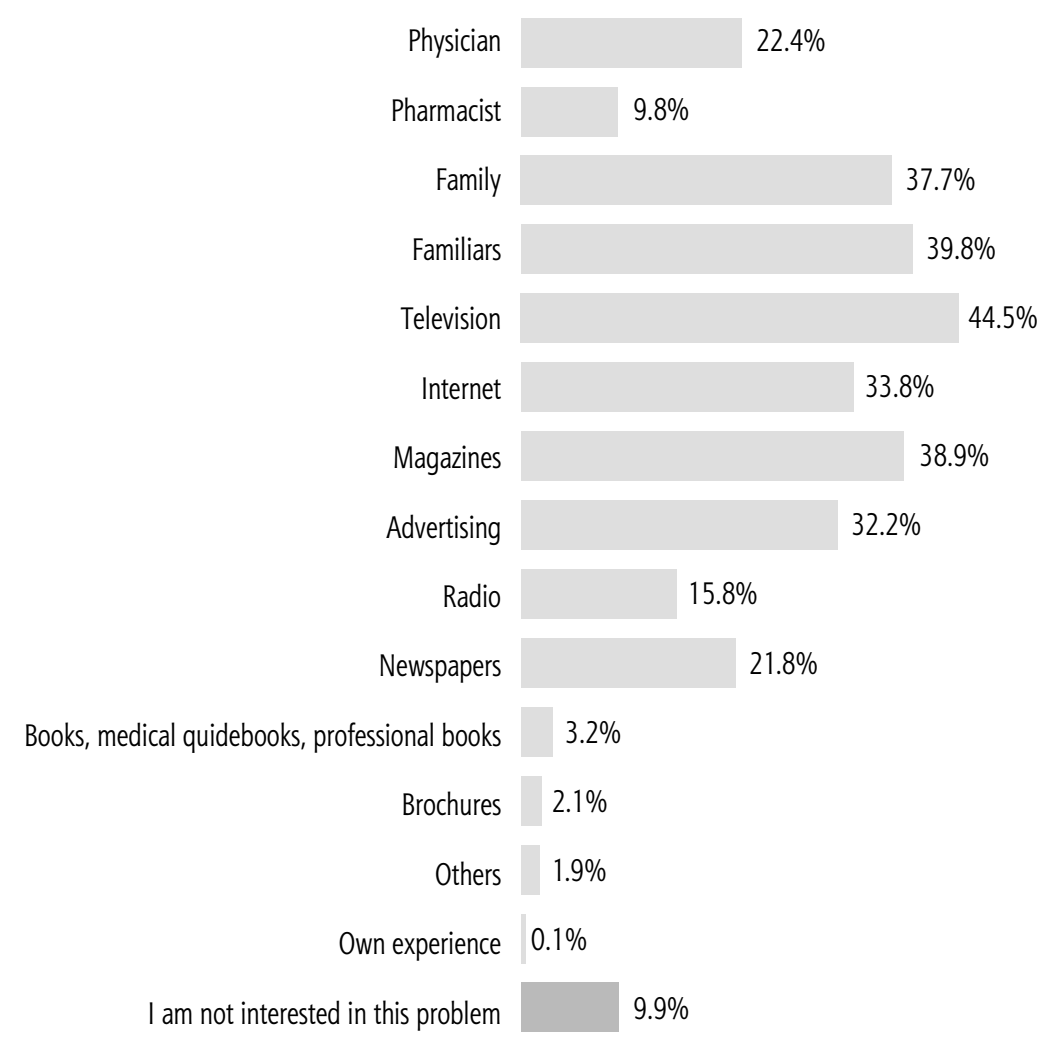

Fig. 2. The sources of knowledge about varicose veins and their complications, prophylaxis, and treatment

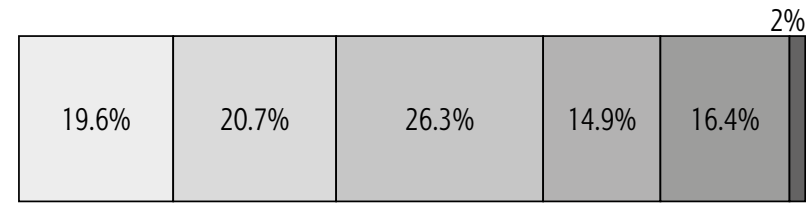

$\square 1$ - I am not informed
$\square 2$
$\square 3$
$\square 4$
$\square 5$ - I am fully informed
$\square$ I do not know

Fig. 3. The results for the question "How do you assess your knowledge, and what should you do if CVD-related complaints occur?"

an important but still underestimated problem for the health of the population $[5,10-15]$. According to previous epidemiological studies, the high prevalence of venous diseases in the populations of the Western world correlates with the high prevalence of symptomatic patients. In this context, not only should the presence of varicose veins and trophic changes be considered, but the high prevalence of the symptoms related to CVD that are subjectively reported by patients, such as leg swelling, fatigue, cramps, and itching, should also be accounted for in CVD [9-12]. The presence of the above-mentioned symptoms can significantly influence patients' quality of life as well as work and social activities [9, 15-19]. It should also be empha-

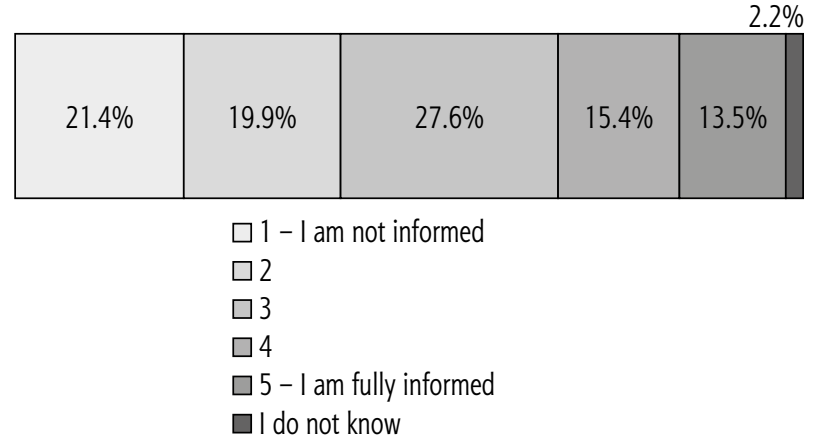

Fig. 4. Results for the question "How do you assess the level of your knowledge concerning prophylaxis for chronic venous disease?"

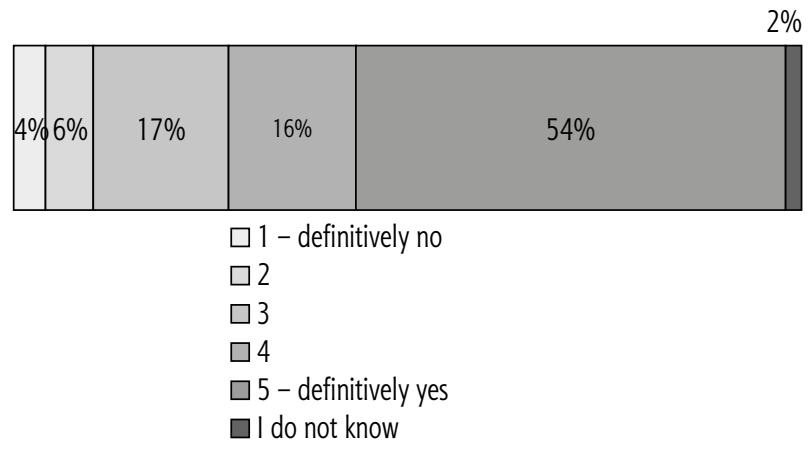

Fig. 5. Results for the question "Do you think that problems associated with chronic venous disease and its prophylaxis and treatment should be given more exposure and promotion in the media?" 


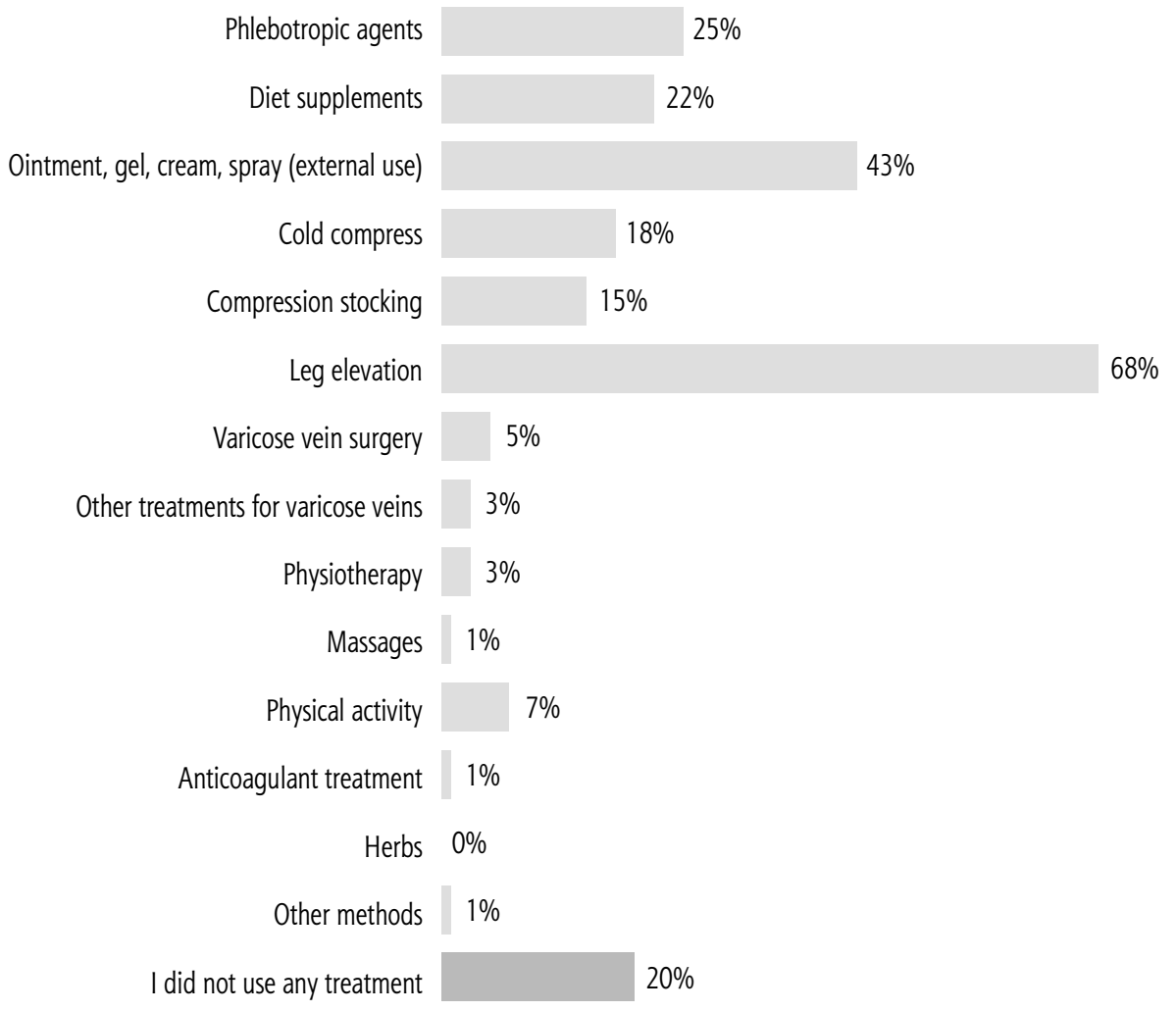

Fig. 6. CVD treatment methods in the symptomatic patient group

sised that these problems and complaints occur in the patients with no visible pathologies, such as varicose veins or swelling, on physical examination. In a study performed in Italy with a group of 1031 patients, varicose veins were found in $22.6 \%$ of the patients, and another $15.8 \%$ reported subjective complaints without varicose veins, but US-diagnosed saphenous vein reflux was found in the latter group. Additionally, in the same study, $15.9 \%$ of the patients suffered from CVD-related complaints without visible varicose veins or reflux documented upon duplex Doppler examination $\left(\mathrm{C}_{\mathrm{S}}\right)$ [18]. Regarding patients with greater than $\mathrm{C} 0$ class disease advancement, there are increasing numbers of studies that document increases in CVD class in addition to a correlation between advanced patient age and a greater prevalence of CVD symptoms [10, 20, 21].

In light of the above-mentioned information, our study results also confirm the very high prevalence of symptoms and signs that are potentially related to CVD in the female population. Among the 604 respondents, only $13 \%$ did not suffer from any lower leg complaints, and $70 \%$ of the cases reported feelings of heaviness and fatigue after long periods of standing or sitting (leg pain after long periods of standing or sitting were reported by $37 \%$, and cramps were reported by $46 \%$ the of cases). In the study population leg swelling was also relatively common, especially in patients with other signs or symptoms of CVD. In the group of patients with varicose veins, pain and swelling occurred in more than $50 \%$ of the population. According to the patients' answers, the majority of subjects who reported symptoms and signs of CVD also reported that these symptoms and signs constituted significant health problems (only $28 \%$ of the symptomatic respondents did not consider the symptoms and signs to problems that influenced their daily activities).

Similar to the high prevalence of symptomatic patients in our study, high prevalences of chronic venous disease in Western world populations have also been reported in other studies. In the Bonn Vein Study, which included a group of 3072 patients aged 18-79 years, CVD-related symptoms (such as feelings of heaviness, fatigue, or pain) were found in $48 \%$ of males and $62 \%$ of females. In the same study, leg swelling occurred in $13.4 \%$ of the study group [17]. In a study performed in Italy (the 24 Cities Cohort Study), a population of 5247 patients was investigated, and $64.8 \%$ of the patients had class $\mathrm{C} 1$ diagnoses and $43 \%$ had $\mathrm{C} 2$ diagnoses [22]. The Edinburgh study was a cross-sectional study of $1566 \mathrm{sub}-$ jects aged 18 to 64 years from the general population of Edinburgh, Scotland, and the telangiectasia and reticular veins were found in approximately $80 \%$ of the men and $85 \%$ of the women. Moreover, in the same population, varicose veins were present in $40 \%$ of the men and $16 \%$ of the women, and ankle oedema was diagnosed in 7\% of the men and $16 \%$ of the women [23]. In the San Diego 
Population Study, which was performed in California, the presence of varicose veins in the female population was reported to be $27.7 \%$, trophic changes occurred in $5.3 \%$, and telangiectasia was found in $55.9 \%$ [24]. In another study conducted by the American Venous Forum in the USA, a population of 2234 patients (mean age: 60 years) was investigated. Class $\mathrm{C} 0$ chronic venous disease was reported in $29 \%, \mathrm{C} 1$ in $29 \%, \mathrm{C} 2$ in $23 \%, \mathrm{C} 3$ in $10 \%$, $\mathrm{C} 4$ in $9 \%, \mathrm{C} 5$ in $1.5 \%$, and C6 in $0.5 \%$ of the study population [25]. In Spain, a research project (the Vein Consult Program) included 19,800 patients who consulted with GPs. The reported prevalence of chronic venous disease (CVD, classes C1-C6) was $48.5 \%$ in the entire population, and the prevalence was significantly higher in the females $(58.5 \%)$ than in the males $(32.1 \%)$ [26]. High prevalences of chronic venous disease have also been reported by other researchers [27-35].

In the present study, we sought reasons for the high prevalence of symptomatic patients, and some of the potentially related factors should be investigated. In this context, patient education and knowledge about CVD prophylaxis tools and treatment possibilities and the possibilities for accessing specialist medical care should be taken into consideration. In our study, among the symptomatic women, only $35.3 \%$ decided to visit physicians for lower leg complaints. In contrast, only $33.8 \%$ of the patients of the general population who had ever consulted their GPs (independent on the reason for the consultation) had been asked about any complaints related to the lower legs (including potential CVD-related symptoms). The low awareness of CVD among medical staff seems also to have other consequences; based on the patient responses, many of the patients did not receive proper and clear information about CVD pathophysiology, prophylaxis and treatment methods. According to our results, only $22.4 \%$ of the respondents received or were receiving knowledge about chronic venous disease from their physicians. More commonly, information was obtained from educational sources, such as TV, radio, and the Internet, or from relatives. Consequently, many of the respondents to our study summarised their knowledge concerning CVD as unsatisfactory and insufficient.

Among the factors that are related to the high rate of symptomatic patients and the unsatisfactory management of this group of patients are the lack of proper treatment and prophylaxis method implementation in daily practice. Of course, these deficiencies can be related to many coexisting factors including access to specialist medical care, self-treatment on the part of patients, and insufficient patient awareness and knowledge. Our study results indicate that pharmacological treatments, including local or systemic drug administration, and the administration of diet supplements are the main therapeutic approaches to CVD-related complaints. Compression treatment in this patient group was very seldom used. More frequent- ly used self-treatment methods included leg elevation. This information is also important in terms of the chronic nature of the disease and the typically long period required for treatment $[12,13,20,23]$. In our study, the duration of varicose veins was greater than 20 years and $10-20$ years in $33.2 \%$ and $23 \%$ of the patients, respectively. These findings at least partially explain the still very significant numbers of patients who visit physicians during the very advanced stage of the disease; i.e. the lack of proper prophylaxis and early therapeutic intervention and the lack of proper knowledge and patient education concerning prophylactic tools can result in the progressive disease worsening and the occurrence of complications. Therefore, improvements in access to specialist care should be combined with broader education of the patient population about the symptoms and signs of CVD and prophylactic methods for preventing CVD. Currently, due to a lack of knowledge, many of the commonly occurring symptoms of CVD are ignored by patients. Moreover, in cases involving more severe complications of CVD, such as venous ulcers and superficial or deep vein thromboses, patients are often seen very late by physicians.

Some limitations of our study should be mentioned. The limitations are mostly related to the design of the study (i.e. telephone and computer-supported interviews). The questions prepared and given to the respondents mostly focused on chronic venous disease symptoms and signs. There was no verification of the diagnoses direct physical examinations conducted by a physician. Despite this limitation and despite the potential presence of other disease diagnoses in the study group, the scale of the documented problem assessed in this representative group of Polish females is suggestive of the need for increased awareness of lower leg vascular diseases among medical staff and the patient population of our country.

\section{CONCLUSIONS}

Despite progress in medical science, the high prevalence of chronic venous diseases and the low level of public awareness in this field justify activities that lead to widespread knowledge about prophylaxis and treatment possibilities for chronic venous disease. This education should be strongly supported by medical staff awareness in the field of CVD diagnosis and the complications of CVD among general practitioner offices and specialist care centres.

The authors declare no conflict of interest.

\section{References}

1. Rabe E., Pannier F. Epidemiology of chronic venous disorders. Handbook of the venous disorders. Gloviczki P. (ed.). Hodder Arnold, London 2009. 
2. Ruckley C.V. Socioeconomic impact of chronic venous insufficiency and leg ulcers. Angiology 1997; 48: 67-69.

3. Van den Oever R., Hepp B., Debbaut B., Simon I. Socio-economic impact of chronic venous insufficiency. An underestimated public health problem. Int Angiol 1998; 17: 161-167.

4. KurzX., KahnS.R., Abenhaim L., ClementD., Norgren L., BaccagliniU., Berard A., Cooke J.P., Cornu-Thenard A., Depairon M., Dormandy J.A., Durand-Zaleski I., Fowkes G.R., Lamping D.L., Partsch H., Scurr J.H., Zuccarelli F. Chronic venous disorders of the leg: epidemiology, outcomes, diagnosis and management. Summary of an evidence based report of the VEINES task force. Venous Insufficiency Epidemiologic and Economic Studies. Int Angiol 1999; 18: 83-102.

5. Jawień A., Grzela T., Ochwat A. Prevalence of chronic venous insufficiency in men and women in Poland: multicenter cross-sectional study in 40095 patients. Phlebology 2003; 18: 110-121.

6. Chudek J., Mikosiński J., Kobielski A., Hering A., AleksiejewKleszczyński T., Umiński J., Zubilewicz T., Kobusiewicz W., Iłżecki M., Wojtak A., Stec J., Urbanek T. Patients' satisfaction with therapy methods of advanced chronic venous disease. Int Angiol 2016; 35: 98-107.

7. Ziaja D., Kocełak P., Chudek J., Ziaja K. Compliance with compression stockings in patients with chronic venous disorders. Phlebology 2011; 26: 353-360.

8. Ziaja D., Chudek J., Maruszyński M., Sieroń A., Molski S., Biolik G., Grzymała J., Stołtny-Sierioń K., Miłosz-Wieczorek B., Tkocz M., Ziaja K. Effectiveness of using micronised diosmin - Diosminex in the treatment of chronic venous insufficiency in the Polish population - results of a multi-site observational study. Chirurgia Polska 2012; 14: 14-23.

9. Sudoł-Szopińska I., Bogdan A., Szopiński T., Panorska A.K., Kołodziejczak M. Prevalence of chronic venous disorders among employees working in prolonged sitting and standing postures. Int J Occup Saf Ergon 2011; 17: 165-173.

10. Jawien $A$. The influence of environmental factors in chronic venous insufficiency. Angiology 2003; 54 Suppl 1: 19-31.

11. Guex J.J., Myon E., Didier L., Nguyen Le C., Taieb C. Chronic venous disease: health status of a population and care impact on this health status through quality of life questionnaires. Int Angiol 2005; 24: 258-264.

12. Eberhardt R.T., Raffetto J.D. Chronic venous insufficiency. Circulation 2005; 111: 2398-2409.

13. Gloviczki P., Comerota A.J., Dalsing M.C., Eklof B.G., Gillespie D.L., Gloviczki M.L., Lohr J.M., McLafferty R.B., Meissner M.H., Murad M.H., Padberg F.T., Pappas P.J., Passman M.A., Raffetto J.D., Vasquez M.A., Wakefield T.W. The care of patients with varicose veins and associated chronic venous diseases: Clinical practice guidelines of the Society for Vascular Surgery and the American Venous Forum. J Vasc Surg 2011; 53: 2S-48S.

14. Allegra C. Updating guidelines in chronic venous disease: what is needed? Medicographia 2011; 33: 238-245.

15. Robertson L., Evans C., Fowkes F.G. Epidemiology of chronic venous disease. Phlebology 2008; 23: 103-111.

16. Jantet G. Chronic venous insufficiency: worldwide results of the RELIEF study. Reflux assessment and quality of life improvement with micronized flavonoids. Angiology 2002; 53: 245-256.

17. Rabe E., Pannier-Fischer F., Bromen K., Schuldt K., Stang A., Poncar C., Wittenhorst M., Bock E., Weber S., Jöckel K.-H.
Bonner Venenstudie der Deutschen Gesellschaft für Phlebologieepidemiologische Untersuchung zur rage der Häufigkeit und Ausprägung von chronischen Venenkrankheiten in der städtischen und ländlichen Wohnbevölkerung. Phlebologie 2003; 32: 1-14.

18. Andreozzi G.M. Prevalence of patients with chronic venous disease- related symptoms but without visible signs (described as $\mathrm{C} 0$ s in the CEAP classification): the Italian experience. Phlebolymphology 2006; 13: 28-35.

19. Kröger K., Ose C., Rudofsky G., Roesener J., Hirche H. Symptoms in individuals with small cutaneous veins. Vasc Med 2002; 7: 13-17.

20. Allegra C. Updating guidelines in chronic venous disease: what is needed? Medicographia 2011; 33: 238-245.

21. Urbanek T., Dorobisz A., Gabriel M., Hendiger W., Jawień A., Kucharzewski M., Madycki G., Rybak Z., Staszkiewicz W., Zubilewicz T., Ziaja K. Assessment of public awareness in the field of epidemiology, prevention and treatment of chronic venous diseases in Poland. Phlebological Review 2015; 23: 45-53.

22. Chiesa R., Marone E.M., Limoni C., Volonté M., Schaefer E., Petrini O. Chronic venous insufficiency in Italy: the 24-cities cohort study. Eur J Vasc Endovasc Surg 2005; 30: 422-429.

23. Evans C.J., Fowkes F.G., Ruckley C.V., Lee A.J. Prevalence of varicose veins and chronic venous insufficiency in men and women in the general population: Edinburgh Vein Study. J Epidemiol Community Health 1999; 53: 149-153.

24. Criqui M.H., Jamosmos M., Fronek A., Denenberg J.O., Langer R.D., Bergan J., Golomb B.A. Chronic venous disease in an ethnically diverse population - The San Diego Population Study. Am J Epidemiol 2003; 158: 448-445.

25. McLafferty R.B., Passman M.A., Caprini J.A., Rooke T.W., Markwell S.A., Lohr J.M., Meissner M.H., Eklöf B.G., Wakefield T.W., Dalsing M.C. Increasing awareness about venous disease: the American Venous Forum expands the national venous screening program. J Vasc Surg 2008; 48: 394-399.

26. Rodriguez J.W., Quesada F., Montoya S.B. Prevalence and clinical characteristics of chronic venous disease in patients seen in primary care in Spain: results of the International Study Vein Consult Program. Cir Esp 2014; 92: 539-546.

27. Beebe-Dimmer J.L., Pfeifer J.R., Engle J.S., Schottenfeld D. The epidemiology of chronic venous insufficiency and varicose veins. Ann Epidemiol 2005; 15: 175-184.

28. Milic D. Prevalence and socioeconomic data in chronic venous disease: how usefull are they in planning appriopriate management. Medicographia 2011; 3: 253-258.

29. Carpentier P.H., Maricq H.R., Biro C., Ponçot-Makinen C.O., Franco A. Prevalence, risk factors and clinical patterns of chronic venous disorders of lower limbs: a population based study in France. J Vasc Surg 2004; 40: 650-659.

30. Novo S., Afellone G., Pinto A., et al. Prevalence of primitive varicose veins of lower limbs in a randomised population sample of Western Sicily. Int Angiol 1988; 7: 176-181.

31. Canonico S., Gallo C., Paolisso G., Pacifico F., Signoriello G., Sciaudone G., Ferrara N., Piegari V., Varricchio M., Rengo F. Prevalence of varicose veins in an Italian elderly population. Angiology 1998; 49: 129-135.

32. Sisto T., Reunanen A., Laurikka J., Impivaara O., Heliövaara M., Knekt P., Aromaa A. Prevalence and risk factors of varicose veins in lower extremities: mini-Finland health survey. Eur J Surg 1995; 161: 405-414. 
33. Nelzén O., Bergqvist D., Lindhagen A. The prevalence of chronic lower-limb ulceration has been underestimated: results of a validated population questionnaire. Br J Surg 1996; 83: 255-258.

34. Moffatt C.J., Franks P.J., Doherty D.C., Martin R., Blewett R., Ross F. Prevalence of leg ulceration in a London population. QJM 2004; 97: 431-437.

35. Lafuma A., Fagnani F., Peltier-Pujol F., Rauss A. Venous disease in France: an unrecognized public health problem. J Mal Vasc 1994; 19: 185-189. 